\title{
ESTRUTURA PRODUTIVA SETORIAL DA COSTA SUL DO ESTADO RIO GRANDE DO SUL: UMA ABORDAGEM COM INSUMO PRODUTO
}

Rodrigo da Rocha Gonçalves ${ }^{1}$ Cassius Rocha de Oliveira ${ }^{2}$ Fernanda Lopes Johnston ${ }^{3}$

Resumo: O objetivo deste artigo foi estimar uma Matriz Insumo Produto da Costa Sul do Rio Grande do Sul buscando conhecer o perfil econômico da região a partir dos indicadores de análise. Os resultados dos multiplicadores de renda e emprego indicaram que os setores de maior impacto foram: produção florestal, pesca e aquicultura; armazenagem e correio; construção; comércio; agricultura e silvicultura e transporte de carga rodoviário. Além disso, foram considerados setores chaves da região com base nos índices de ligação: construção; outros serviços; produtos de madeira - exclusive móveis; água, esgoto e gestão de resíduos; fabricação de químicos, resinas, elastômeros e outros equipamentos de transporte. Em linhas gerais, tem grande representatividade na região as atividades relacionadas à produção florestal, atividade portuária e agronegócio.

Palavras-chave: Matriz Insumo Produto. Costa Sul do Rio Grande do Sul. Indicadores de análise.

\section{SECTORAL PRODUCTION STRUCTURE OF THE SOUTH COAST OF THE STATE RIO GRANDE DO SUL/BR: AN APPROACH WITH INPUT OUTPUT}

Abstract: The objective of this paper was to estimate an Input Output Matrix of the South Coast of Rio Grande do Sul State in Brazil, to know the economic profile from the analysis indicators. The results of the income and employment multipliers indicated that the sectors with the greatest impact were: forest production, fishing and aquaculture; storage and mail; construction; trade; agriculture and forestry and road freight transport. In addition, key sectors of the region were considered based on the following indices: construction; other services; wood products - excluding furniture; water, sewage and waste management; manufacturing of chemicals, resins, elastomers and other transportation equipment. In general terms, activities related to forestry production, port activity and agribusiness are highly representative.

Keywords: Matrix Input Output. South Coast of Rio Grande do Sul. Analysis Indicators.

\section{ESTRUCTURA PRODUCTIVA SECTORIAL DE LA COSTA SUR DEL ESTADO RIO GRANDE DO SUL UM ENFOQUE COM INSUMO Y PRODUCTO}

\footnotetext{
${ }^{1}$ Universidade Federal do Rio Grande, ICEAC, Rio Grande, Brasil, rrochagoncalves@gmail.com. https://orcid.org/0000-0003-0596-5576.

2 Universidade Federal do Rio Grande, ICEAC, Rio Grande, Brasil, oliveiracassius@yahoo.com.br. https://orcid.org/0000-0003-4888-4872.

3 Universidade Federal do Rio Grande, ICEAC, Rio Grande, Brasil, fernandajohnston@hotmail.com. https://orcid.org/0000-0001-8414-2409.
} 
Resumen: El objetivo de este trabajo fue estimar una Matriz de Insumo y Producto de la Costa Sur del Estado de Rio Grande do Sul en Brasil, para conocer el perfil económico de los indicadores de análisis. Los resultados de los multiplicadores de ingresos y empleo indicaron que los sectores con mayor impacto fueron: producción forestal, pesquería y acuicultura; almacenamiento y correo; construcción; comercio; agricultura y silvicultura y transporte de mercancías por carretera. Además, los sectores clave de la región se consideraron con base en los siguientes índices: construcción; otros servicios; productos de madera - muebles exclusivos; agua, alcantarillado y manejo de desechos; fabricación de productos químicos, resinas, elastómeros y otros equipos de transporte. En términos generales, las actividades relacionadas con la producción forestal, la actividad portuaria y los agronegocios son altamente representativas.

Palabras clave: Matriz Insumo Produto. Costa sur del Rio Grande do Sul. Indicadores de Analisis.

Introdução

A Costa Sul é uma das áreas menos conhecidas e habitadas do litoral gaúcho e brasileiro. A região é composta pelos municípios de Santa Vitória do Palmar, Rio Grande, São José do Norte, Tavares e Mostardas e, possui aproximadamente $400 \mathrm{~km}$ de costa entre os molhes da barra do Chuí em Santa Vitória do Palmar e o distrito da Solidão em Mostardas.

Uma das principais características desta localidade é seu riquíssimo ecossistema litorâneo que compreende a laguna dos Patos e o seu estuário no município do Rio Grande composto por um dos maiores portos do Brasil, a binacional lagoa Mirim, a lagoa do Peixe entre Tavares e Mostardas, a lagoa Mangueira em Santa Vitória do Palmar, a estação ecológica do Taim além de centenas de quilômetros de praias desertas.

Além de compreender uma extensa faixa de restinga, onde se localizam sete faróis de sinalização para navegação, dunas com vegetação e bioma particular conhecido como concheiros $^{4}$, a fauna presente nesta região inclui centenas de espécies de aves marinhas migratórias, mamíferos marinhos de grande porte, inúmeras espécies de peixes, moluscos e crustáceos.

A atividade econômica do local é caracterizada principalmente pelo agronegócio, que se estende por grande parte da região e, também, pela silvicultura onde ocorrem as retiradas de resinas e madeiras. Além disso, as partes lagunares,

\footnotetext{
${ }^{4}$ Acúmulo de conchas limpas pela ação das correntes e que muitas vezes vão parar na praia e outras são levadas novamente para o mar.
} 
oceânicas e estuarinas são exploradas pela pesca artesanal e industrial que, desde a década de 1940 atua na região.

Já no estuário da laguna dos Patos em Rio Grande, existe intensa atividade portuária que comporta várias indústrias, como a de fertilizantes, processamento de soja, refinaria de petróleo, processamento de pescado, polo naval, metalurgia entre outras, além das atividades comerciais e de transportes de cargas. Por fim, a atividade turística é praticada principalmente nos balneários: Cassino, Hermenegildo, Barra do Chuí, Mar Grosso, Mostardas, entre outros.

Diante disso surge uma pergunta: como o entendimento da estrutura produtiva favorece a formulação de políticas públicas para a região, possibilitando um conhecimento das características econômicas da Costa Sul do Estado do Rio Grande do Sul?

Dessa forma, o objetivo do estudo é estimar uma Matriz Insumo Produto (MIP) da Costa Sul do Rio Grande do Sul, buscando conhecer o perfil econômico a partir dos indicadores de análise. A matriz foi regionalizada utilizando o método do Quociente Locacional partindo de uma matriz calculada para o Rio Grande do Sul em 2011, baseada na estrutura setorial da matriz 2010 nacional. Foram utilizados dados do IBGE 2011 e da Relação Anual de Informações Sociais (RAIS).

$O$ artigo está estruturado em cinco seções, além desta introdução. Na segunda seção apresenta-se a Costa Sul do Rio Grande do Sul. Após, na seção três, realizase uma breve revisão de literatura sobre Matriz Insumo Produto e os procedimentos adotados para a estimação da matriz da região. Já na quarta seção, são apresentados e discutidos os resultados dos indicadores econômicos, tais como, índices de ligação e multiplicadores. Por fim, a quinta seção, é composta pelas considerações finais.

\section{A Costa Sul do Rio Grande do Sul}

Conforme o mapa 1, além de se observar a área de estudo destacada em vermelho, pode-se analisar também as grandes lagoas, representadas em azul, bem como a produção de floresta, em verde. 
Mapa 1: Costa sul do Estado do Rio Grande do Sul

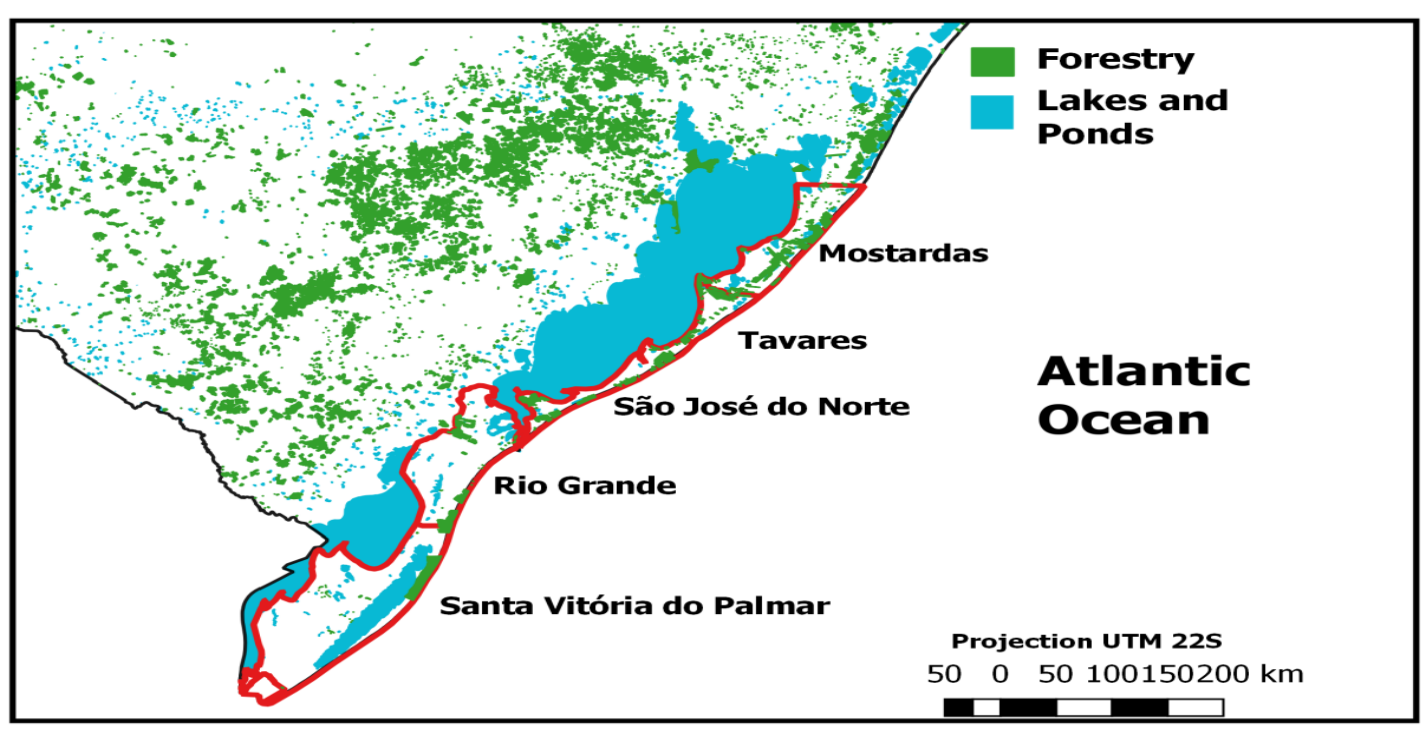

Fonte: Elaboração dos autores.

Como podemos ver na tabela 1, o município do Rio Grande possui a maior população e se destaca como a maior economia da região, apesar de apresentar a maior taxa de mortalidade infantil. Já o município de Santa Vitória possui a maior área entre os citados, entretanto, com baixíssima densidade populacional. Ademais, os altos níveis de analfabetismo no município de São José do Norte chamam a atenção e instigam políticas públicas neste sentido. Com relação a participação no PIB destacam-se os municípios de Rio Grande e Santa Vitória do Palmar, ambos concentram em torno de $91 \%$ da renda gerada na região.

Tabela 1: Características dos municípios estudados

\begin{tabular}{l|c|c|c|c|c|c|c}
\hline Município & Pop. & Área km & Dens. D & Analfabetismo & Ex. Vida & $\begin{array}{c}\text { M. } \\
\text { Infantil }\end{array}$ & PIB R\$ \\
\hline St Vitória & $\mathbf{3 2 . 3 2 6}$ & $\mathbf{5 . 2 4 4 , 4}$ & $\mathbf{5 , 8}$ & $\mathbf{6 , 4 6 \%}$ & $\mathbf{7 6 , 6}$ & $\mathbf{2 , 2 6}$ & $834.362,24$ \\
\hline R. Grande & 214.532 & $2.709,5$ & 73,8 & $\mathbf{4 , 6 5 \%}$ & $\mathbf{7 6 , 6}$ & 15,03 & $7.274 .579,59$ \\
\hline S. J. Norte & 26.424 & $1.118,1$ & 23,2 & $\mathbf{1 7 , 3} \%$ & $\mathbf{7 2 , 5}$ & 3,30 & $351.389,82$ \\
\hline Tavares & 5.430 & 604,3 & $\mathbf{8 , 9}$ & $\mathbf{1 4 , 4 \%}$ & $\mathbf{7 4 , 6 9}$ & $\mathbf{n . d}$ & $74.923,54$ \\
\hline Mostardas & 12.583 & $1.983,0$ & $\mathbf{6 , 2}$ & $\mathbf{1 1 , 3 1 \%}$ & $\mathbf{7 5 , 9 4}$ & $\mathbf{8 , 2}$ & $283.361,84$ \\
\hline
\end{tabular}

Fonte: Fundação de Economia e Estatística 2015. 
Na tabela 2, o PIB em 2011 da Costa Sul foi de, aproximadamente, $R \$ 6.392,73$ milhões. Segundo dados da Matriz Insumo Produto, os setores mais relevantes na sua composição foram: produção florestal, pesca e aquicultura; comércio; administração pública; fabricação de químicos, resinas e elastômeros; agricultura, silvicultura; outros equipamentos de transporte; construção e outros.

\section{Tabela 2: Composição do PIB da Costa Sul do Rio Grande do Sul}

\begin{tabular}{|c|c|c|c|}
\hline Setores & Part.\% & Setores & Part.\% \\
\hline Agricultura, silvicultura & $5,47 \%$ & Manutenção, reparação e instalação de máq. & $0,76 \%$ \\
\hline Pecuária inclusive apoio & $0,89 \%$ & Energia elétrica, gás natural e utilidades & $1,51 \%$ \\
\hline Produção florestal, pesca e aquicultura & $15,56 \%$ & Água, esgoto e gestão de resíduos & $0,95 \%$ \\
\hline Extração de carvão mineral & $0,00 \%$ & Construção & $4,31 \%$ \\
\hline Extração de Petróleo e gás natural & $0,00 \%$ & Comércio & $12,28 \%$ \\
\hline Extr. de minerais metálicos não ferrosos & $0,00 \%$ & Transporte de carga ferroviário & $0,08 \%$ \\
\hline Abate e produtos & $0,07 \%$ & Transporte de carga rodoviário & $0,85 \%$ \\
\hline Fabricação e refino de açúcar & $0,00 \%$ & Transporte de carga hidroviário & $0,24 \%$ \\
\hline Outros produtos alimentares & $0,22 \%$ & Transporte de carga aeroviário & $0,00 \%$ \\
\hline Fabricação de bebidas & $0,00 \%$ & Demais transportes de carga & $6,16 \%$ \\
\hline Produtos do fumo & $0,00 \%$ & Transporte rodoviário de passageiros & $0,08 \%$ \\
\hline Setores & Part.\% & Setores & Part.\% \\
\hline Têxteis & $0,02 \%$ & Transporte hidroviário de passageiros & $0,04 \%$ \\
\hline Artigos do vestuário e acessórios & $0,05 \%$ & Transporte ferrov. e met. de passageiros & $0,00 \%$ \\
\hline Fabricação de calçados e couro & $0,00 \%$ & Transporte aeroviário de passageiros & $0,00 \%$ \\
\hline Produtos de madeira - exclusive móveis & $0,73 \%$ & Demais transporte de passageiros & $0,78 \%$ \\
\hline Fabr. de celulose e produtos de papel & $0,00 \%$ & Armazenagem e correio & $2,46 \%$ \\
\hline Impressão e reprodução de gravações & $0,03 \%$ & Alojamento & $0,29 \%$ \\
\hline Refino de petróleo e coque & $4,49 \%$ & Alimentação & $1,50 \%$ \\
\hline Fabricação de biocombustíveis & $0,00 \%$ & Edição, edição integrada e impressão & $0,15 \%$ \\
\hline Fabricação de químicos e resinas e elast. & $6,53 \%$ & Ativ. de televisão, rádio, cinema, som e imag. & $0,35 \%$ \\
\hline Defensivos agrícolas, tintas e químicos & $0,14 \%$ & Telecomunicações & $1,35 \%$ \\
\hline Perfumaria, higiene e limpeza & $0,04 \%$ & Des. de sistema e outros serviços de infor. & $0,53 \%$ \\
\hline Produtos farmoquímicos farmacêuticos & $0,00 \%$ & Intermediação financeira e seguros & $4,08 \%$ \\
\hline Artigos de borracha e plástico & $0,00 \%$ & Serviços imobiliários e aluguel & $3,01 \%$ \\
\hline Fabr. de produtos de minerais $n$. met. & $0,05 \%$ & Ativ. jurídicas, contábeis e consultoria e sedes & $1,09 \%$ \\
\hline Fabricação de aço e derivados & $0,00 \%$ & Serv. arquitetura, engenharia, testes e P\&D & $0,33 \%$ \\
\hline Metalurgia de metais não-ferrosos & $0,00 \%$ & Out. atividades profissionais, cientificas & $0,76 \%$ \\
\hline Prod. de metal -exclusive máquinas e eq. & $0,23 \%$ & Alug. não imobiliário e gestão de propriedade & $0,62 \%$ \\
\hline Fabr. de equipamentos eletrônicos, inf. & $0,00 \%$ & Outras atividades administrativas & $0,31 \%$ \\
\hline Fabr. de equipamentos elétr. e eletrod. & $0,00 \%$ & Ativ. de vigilância, segurança e investigação & $0,40 \%$ \\
\hline Máquinas e equipamentos & $0,03 \%$ & Administração Pública & $7,93 \%$ \\
\hline Fabr. de automóveis, caminhões e ônibus & $0,00 \%$ & Educação mercantil & $2,35 \%$ \\
\hline
\end{tabular}




\begin{tabular}{l|r|l|r} 
Peças e acessórios para veículos aut. & $0,03 \%$ & Saúde mercantil & $2,46 \%$ \\
Outros equipamentos de transporte & $5,01 \%$ & Outros serviços & $2,38 \%$ \\
Móveis e produtos das indústrias diversas & $0,00 \%$ & Serviços domésticos & $0,02 \%$ \\
\hline Total & $\mathbf{3 9 , 6 0 \%}$ & & $\mathbf{6 0 , 4 0 \%}$ \\
\hline
\end{tabular}

Fonte: Resultados da Matriz Insumo Produto da Costa Sul.

\section{Matriz Insumo Produto}

Nesta seção serão apresentadas as definições teóricas, evidências empíricas e procedimentos para estimação da MIP da Costa Sul.

\section{Matriz Insumo Produto: Definições teóricas e evidências empíricas}

A abordagem de matriz insumo produto (MIP) consiste num arcabouço analítico que mapeia as relações intersetoriais dos agentes que compõe o sistema econômico, sendo considerada uma ferramenta de planejamento econômico, disponível ao formulador de política pública. A partir desse instrumental, pode-se avaliar o impacto de políticas setoriais e seus efeitos sobre uma economia nacional e/ou regional.

Os trabalhos iniciais de MIP são fundamentados e inspirados nas contribuições de Quesnay sobre o fluxo circular de renda e no modelo de equilíbrio geral simplificado proposto por Walras. O economista e matemático Wasily Leontief foi o pioneiro com a formulação do modelo de insumo produto em seu artigo seminal em (1936), construindo um instrumental que possibilitou uma análise sobre as relações intersetoriais na produção.

O modelo básico (produção) de Leontief é geralmente construído a partir de dados para uma região geográfica específica (nação, regional, mesorregião e etc.). A informação fundamental utilizada na análise diz respeito aos fluxos de produtos de cada setor econômico, considerado produtor e/ou consumidor cada um dos setores, dado as interações setoriais. Conforme Miller e Blair (2009) as linhas descrevem a distribuição da produção de um produtor em toda a economia (vendas) e as colunas a composição dos insumos exigidos por um determinado setor produzir um produto (compras).

O modelo de produção permite a comparação entre os impactos que a adoção de determinadas políticas tem sobre uma nação e/ou uma região e quais as 
repercussões intersetoriais, partindo da pressuposição que ocorreram modificações na demanda final. Dessa forma, dado o encadeamento dos setores da economia em análise, pode-se verificar quais setores são impactados, quais as magnitudes e os setores mais sensíveis a modificações na demanda final.

$X=A X+F$

Sendo: $X$ é o vetor coluna da oferta (produção nacional) e $F$ é o vetor coluna da demanda final. Como no modelo aberto, o vetor da demanda final é considerado uma variável exógena, pode-se resolver o sistema com a equação:

$$
X=B F
$$

Onde: $-1 B=I-A$

e B é a matriz dos coeficiente técnicos diretos e indiretos, mais conhecida como matriz inversa de Leontief.

$$
B=(I-A)^{-1}
$$

A matriz A representa a matriz dos coeficientes técnicos diretos, ou seja, a matriz que fornece o impacto direto causado pelo aumento na demanda final, enquanto que $(I-A)^{-1}$, além dos efeitos diretos, avalia também os indiretos. Portanto, o modelo definido na equação (4) é o que permitirá avaliar o impacto total que uma variação na demanda final causará na produção da economia, dado o aumento da demanda em uma unidade.

Partindo dos multiplicadores da matriz $\mathbf{B}$ de Leontief, diversas análises são realizadas, com relação a variáveis como emprego, renda, produto e etc. Além disso, a partir da matriz $\mathbf{B}$ também se pode encontrar os índices de ligação e setores econômicos chave ${ }^{5}$. A evolução das técnicas de I-P tem permitido a análise de modelos regionais e inter-regionais, sendo necessária para isso a estimação de matrizes insumo produto.

A estrutura de produção de uma determinada região pode ser idêntica ou diferir significativamente de uma matriz nacional, por isso, para aplicações regionais precisase levar em consideração a relação entre os coeficientes técnicos da tabela nacional e da matriz regional a ser estimada. Além disso, quanto menor for a região analisada,

\footnotetext{
${ }^{5}$ Miller e Blair (2009) apresentam formalmente diversos métodos de análise.
} 
mais dependente será essa economia com relação ao comércio externo (MILLER e BLAIR, 2009).

Ademais, as matrizes regionais e/ou inter-regionais possuem às mesmas identidades contábeis de uma matriz nacional, existindo sempre um equilíbrio entre oferta e demanda agregada, porém questões relacionadas ao comércio exterior e ao nível de governo são diferentes, com isso, surgem vetores de importações e exportações regionais e/ou inter-regionais. Wiebusch (2007) menciona que trabalhos com matrizes insumo-produto regionais precisam levar em dados regionais mesmo que os coeficientes técnicos adotados sejam os mesmo a nível nacional.

Nesse sentido, Guilhoto (2011) diz que uma matriz regional apresenta a mesma estrutura de uma matriz nacional, tendo como diferença básica a discriminação da exportação (importação) para as outras regiões do país e a exportação (importação) para outros países. Por sua vez, a matriz de modelos inter-regionais, os quais são inspirados no modelo Isard (1951) requerem uma grande massa de dados reais ou estimados, principalmente quanto às informações sobre fluxos Intersetoriais e interregionais.

Ribeiro (2013) salienta que para a estimação das matrizes regionais, a literatura internacional indica dois métodos: os censitários e os não censitários. Segundo recomendado quando se tem carência de estatísticas regionais, à medida que os métodos censitários possuem uma aplicação complexa e necessitam de uma grande quantidade de informações.

Por outro lado, Ribeiro (2013) salienta que no Brasil destacam-se duas técnicas de regionalização para matrizes de coeficientes técnicos: i) $O$ método do quociente locacional (QL) e ii) O método de biproporcionalidade RAS. O primeiro método considera o ajuste dos coeficientes técnicos a partir da relação entre duas economias a regional e a nacional, geralmente leva em consideração se um determinado setor tem comparativamente uma concentração maior na região ou fora dela, principalmente através do número de empregos. Já o segundo, utiliza as proporções de uma matriz nacional, partindo de estíticas regionais, faz o ajustamento de linhas e colunas, visando garantir o equilíbrio das identidades de contabilidade social. No 
Brasil a literatura de estudos com matrizes insumo produto é extensa, tanto com a estimação de modelos inter-regionais como regionais.

Brene et al. (2011) realizaram um estudo para o munícipio de São Bento do Sul. Sendo estimada a Matriz de Insumo Produto municipal da cidade através do Método do Quociente Locacional buscando calcular os indicadores econômicos para identificar setores-chave para o desenvolvimento econômico e social do município. Os resultados mostraram que o setor de madeira e móveis foi importante na produção e emprego, porém, não aparece como maior multiplicador de produto e renda, com destaque para os setores de siderurgia produto e renda, com destaque para os setores de siderurgia, comércio, serviços prestados à família e administração pública.

Nunes e Melo (2012) estimaram uma Matriz Insumo Produto utilizando o método QL também, para a para Mesorregião Sudeste Paranaense. Os autores elaboraram uma matriz de insumo produto da região Sudeste Paranaense para o ano de 2009, buscando identificar os setores-chave, bem como os efeitos de ligação e multiplicadores de produção, emprego e renda. Como resultado, evidenciaram que, algumas atividades não tradicionais, possuem altos índices de desempenho econômico, os índices de ligação normalizados de Rasmussen-Hirschmann permitiram verificar que oito setores apresentaram índices de ligação para frente maior que um, e doze setores tiveram índices de ligação para trás superiores à unidade e dois setores foram considerados chaves (indústria química e metalurgia). Com relação aos multiplicadores destacaram-se, material elétrico e eletrônico (produção), alimentos e bebidas (renda) e material de transporte (emprego).

Por Fim, Leivas e Feijó (2014), estimaram a Matriz Insumo Produto do Conselho Regional de Desenvolvimento da Região Sul do Estado do Rio Grande do Sul (COREDE), buscando identificar os segmentos-chave para a economia da Região e calculando multiplicadores de impacto intersetorial para a produção, valor adicionado e emprego utilizando o método QL. Segundo os autores os resultados mostraram que a Região apresenta uma economia pouco diversificada e não muito dinâmica, com segmentos-chave relacionados, basicamente, aos setores agroindustriais e de serviços. 
Quanto aos setores-chave, a Região apresentou seis atividades que podem ser consideradas fundamentais, na perspectiva do encadeamento para a frente, isto é, na venda de insumos, quais sejam: agropecuária, silvicultura, exploração vegetal e pesca; refino do petróleo; comércio; transporte; serviços prestados às famílias e às empresas; e indústria química. Por outro lado, os setores-chave com encadeamento para trás, foram: fabricação de óleos vegetais; indústria de laticínios; beneficiamento de produtos vegetais; abate de animais; outros produtos alimentares; transporte; refino do petróleo; indústria química; indústrias diversas; e comércio.

Conforme mencionado, a literatura empírica nacional de insumo produto é vasta, cabendo ainda mencionar as contribuições de Parré (2000) e Talamini e Pedrozo (2004). Com relação a aplicações de modelos regionais de insumo produto no Rio Grande do Sul, cabe mencionar os trabalhos de Porsse et al. (2003) e Porsse et al. (2008) os quais estimam matrizes inter-regionais para o Rio Grande do Sul e o Restante do Brasil a partir de Técnicas RAS. Por outro lado, Wiebusch (2007), Leivas e Feijó (2014) estimam matrizes insumo produto para os COREDEs Vale do Taquari e Sul a partir da regionalização do consumo intermediário pelo Quociente Locacional.

Percebe-se que os métodos RAS e o Quociente Locacional são as principais técnicas utilizadas na regionalização de matrizes insumo produto no Brasil. Observase ainda uma carência de trabalhos que estimam MIPs para regiões costeiras. No caso especifico do Rio Grande do Sul, a literatura empírica indica que não existe nenhum trabalho que estime uma matriz semelhante no estado, isso ressalta a relevância deste trabalho.

Dessa forma, o cálculo de multiplicadores de produto, emprego e renda, impostos etc. proporcionam um conhecimento da estrutura setorial da economia em questão. Sendo o multiplicador de produto $M P_{j}$ a principal referência do nível de atividade econômica, obtido pela soma das colunas de $b_{i j}$, demostra quanto determinado setor coluna $(j)$ pode gerar de produção em todos os setores da economia, de acordo com a alteração de uma unidade monetária da demanda final total, em relação à produção do setor $j$. Formalmente: 
$M P=\sum_{1=i}^{n} b_{i j}$

Tendo $b_{i j}$ como um elementos pertencentes a matriz inversa de Leontief $B$

Além disso, quando se relaciona a variável de interesse com a produção obtémse o coeficiente direto da variável em questão

$$
v_{j}=\frac{V_{j}}{X_{j}}
$$

A partir dos coeficientes diretos apresentando na equação (6) chega-se ao impacto total, direto, e indireto sobre a variável de interesse, definido como geradores:

$$
G V_{j}=\sum_{1=i}^{n} b_{i j} v_{i}
$$

Sendo a variável de interesse valor adicionado, pode-se encontrar o gerador por meio da seguinte equação:

$$
V A_{i x 1}=\sum_{1=i}^{n} b_{i j} v a_{i x 1}
$$

Onde $v a_{i x 1}$ é a razão entre o valor adicionado bruto e o valor bruto da produção, demonstra a variação ocorrida no valor adicionado bruto do setor $i$ devido a uma variação unitária na demanda final. Já a razão entre o gerador $V A_{i x 1}$ e o coeficiente direto $v a_{i x 1}$ é chamado de multiplicador de valor adicionado.

Analogamente, encontram-se os multiplicadores de empregos, salários, impostos e importações, os quais são considerados indicadores de desenvolvimento econômico (qualitativos). Neste trabalho os multiplicadores limitam-se ao consumo intermediário, ou seja, são analisados apenas os indicadores, denominados por Guilhoto (2011), do tipo 1.

Quando o objetivo é verificar como os setores estão interligados nas compras e nas vendas com outros setores, utilizam-se os índices de ligação para trás e para frente. Tais indicadores foram formulados por Rasmussen (1956) e Hirschman (1958), mensuram o poder de dispersão dos encadeamentos a montante, ou para trás, e o índice de sensibilidade de dispersão dos encadeamentos a jusante, ou para frente. 
Desse modo, considerando (B) como a matriz inversa de Leontief, $b_{i j}$ como sendo um elemento da matriz inversa de Leontief, $B^{*}$ como sendo a média de todos os elementos de $(\boldsymbol{B}), b_{j}$ e $b_{i}$ como sendo respectivamente a soma de uma coluna e de uma linha típica de $(\boldsymbol{B})$, tem-se formalmente os índices de ligação para trás e para frente:

Índices de ligações para trás (poder da dispersão):

$U_{j}=\left[B_{j} / n\right] / B^{*}$

Índices de ligações para frente (sensibilidade da dispersão):

$U_{i}=\left[B_{i} / n\right] / B^{*}$

Onde $U_{j}$ é o coeficiente de ligação para trás, o qual mostra quanto é demandado por cada setor em seus encadeamentos para trás, ou seja, quanto um determinado setor compra dos outros setores.

Por outro lado, $U_{i}$ é o coeficiente de ligação para frente, o qual demonstra o quanto é ofertado por cada setor em seus encadeamentos para frente, ou seja, quanto um determinado setor vende para os outros setores da economia.

Conforme Miller e Blair (2009) a partir dos resultados dos índices anteriores, surgem quatro classificações dependendo dos resultados: i) independentes ou pouco relacionados, quando ambos os índices forem inferior a 1; ii) dependentes ou fortemente relacionados, quando os dois índices simultaneamente forem superior a 1; iii) dependentes da oferta interindustrial, quando somente o índice de ligação para trás for maior do que 1 ; e iv) dependentes da demanda interindustrial, quando somente $o$ índice de ligação para frente for superior a 1.

\section{Procedimentos para Estimação da MIP da Costa Sul}

A estimação da Matriz Insumo Produto da Costa Sul foi realizada a partir da utilização do método Quociente Locacional aplicado na matriz do Rio Grande do Sul para o ano de 2011, estimada por Gonçalves (2018). A matriz utiliza a estrutura setorial semelhante a matriz nacional de 2010 e também segue a mesma estrutura teórica. 
Ainda que, a última MIP divulgada de 2010 apresente um detalhamento de produtos e setores, torna-se necessário a compatibilização das contas regionais do IBGE com a Relação Anual de Informações (RAIS) de 2011 sobre o mercado de trabalho da Costa Sul e posteriormente a padronização com a matriz do RS de 2011. A compatibilização da RAIS foi realizada pela CNAE (2.0) classe seguindo expressamente a comissão de classificação do IBGE (CONCLA) as 672 atividades foram classificadas em 70 setores (conforme a tabela 3).

\section{Tabela 3: Estrutura setorial MIP Costa Sul}

\begin{tabular}{|c|c|c|c|}
\hline \multicolumn{2}{|r|}{ SETORES } & \multicolumn{2}{|r|}{ SETORES } \\
\hline 1 & Agricultura, silvicultura & 35 & Móveis e produtos das indústrias diversas \\
\hline 2 & Pecuário inclusive apoio & 36 & Manutenção, reparação e instalação de máq. e equip \\
\hline 3 & Produção florestal, pesca e aquicultura & 37 & Energia elétrica, gás natural e outras utilidades \\
\hline 4 & Extração de carvão mineral & 38 & Água, esgoto e gestão de resíduos \\
\hline 5 & Extração de Petróleo e gás natural & 39 & Construção \\
\hline 6 & Extração de minerais metálicos não ferrosos & 40 & Comércio \\
\hline 7 & Abate e produtos & 41 & Transporte de carga ferroviário \\
\hline 8 & Fabricação e refino de açúcar & 42 & Transporte de carga rodoviário \\
\hline 9 & Outros produtos alimentares & 43 & Transporte de carga hidroviário \\
\hline 10 & Fabricação de bebidas & 44 & Transporte aeroviário de carga \\
\hline 11 & Produtos do fumo & 45 & Demais transportes de cargas \\
\hline 12 & Têxteis & 46 & Transporte rodoviário de passageiros \\
\hline 13 & Artigos do vestuário e acessórios & 47 & Transporte hidroviário de passageiros \\
\hline \multirow[t]{2}{*}{14} & Fabricação de calçados e couro & 48 & Transporte ferrov. e met. de passageiros \\
\hline & SETORES & \multicolumn{2}{|r|}{ SETORES } \\
\hline 15 & Produtos de madeira - exclusive móveis & 49 & Transporte aeroviário de passageiros \\
\hline 16 & Fabricação de celulose e produtos de papel & 50 & Demais transportes de passageiros \\
\hline 17 & Impressão e reprodução de gravações & 51 & Armazenagem e correio \\
\hline 18 & Refino de petróleo e coque & 52 & Alojamento \\
\hline 19 & Fabricação de biocombustíveis & 53 & Alimentação \\
\hline 20 & Fabricação de químicos, e res e elastômeros & 54 & Edição, edição integrada e impressão \\
\hline 21 & Defensivos agrícolas, tintas e químicos div. & 55 & Atividades de televisão, rádio, cinema, grav de som \\
\hline 22 & Perfumaria, higiene e limpeza & 56 & Telecomunicações \\
\hline 23 & Produtos farmoquímicos e farmacêuticos & 57 & Desenvolvimento de sistema e outros serviços de inf. \\
\hline 24 & Artigos de borracha e plástico & 58 & Intermediação financeira e seguros \\
\hline 25 & Fabr. de produtos de minerais não-metálicos & 59 & Serviços imobiliários e aluguel \\
\hline 26 & Fabricação de aço e derivados & 60 & Atividades jurídicas, contábeis e consultoria e sedes \\
\hline 27 & Metalurgia de metais não-ferrosos & 61 & Serviços de arquitetura, engenharia, pesquisa e des. \\
\hline 28 & Produtos de metal - exclusive máq. e equip. & 62 & Outras atividades profissionais, cientificas e técnicas \\
\hline
\end{tabular}




\begin{tabular}{l|l|l|l}
29 & Fabricação de equipamentos eletrônicos, inf. & 63 & Aluguéis não imobiliários e gestão de propriedade \\
30 & Fabr. de equipamentos elétricos e eletrod. & 64 & Outras atividades administrativas \\
31 & Máquinas e equipamentos & 65 & Atividades de vigilância, segurança e investigação \\
32 & Fabr. de automóveis, caminhões e ônibus & 66 & Administração pública e seguridade social \\
33 & Peças e acessórios para veículos automot. & 67 & Educação mercantil \\
34 & Outros equipamentos de transporte & 68 & Saúde mercantil \\
& & 69 & Outros serviços \\
\hline
\end{tabular}

Fonte: Elaboração dos autores.

Segundo Miller e Blair (2009), o método do Quociente Locacional é uma maneira de analisar o nível de especialização dos setores produtivos de uma região, pois ele compara a participação do setor em uma determinada região com uma região maior, ou seja, se o valor encontrado for maior que um, significa que a região é especializada naquele setor e sua produção suficiente para atender o mercado local, produzindo excedentes exportáveis. Por outro lado, se for inferior a um a região não é especializada no setor.

Os resultados dos quocientes locacionais estão na tabela 4 abaixo. Observamos que a região possui uma especialização nos setores de produção florestal, pesca e aquicultura; outros equipamentos de transporte; demais transportes de carga; fabricação de químicos e resinas e elastômeros; refino de petróleo e coque; armazenagem e correio; transporte de carga hidroviário; agricultura, silvicultura; produtos de madeiras e outros.

Tabela 4: Quociente Locacional dos setores da Matriz de Insumo-Produto da Costa Sul

\begin{tabular}{|c|c|c|c|}
\hline SETORES & QL & SETORES & QL \\
\hline Produção florestal, pesca e aquicultura & 44,6816 & $\begin{array}{l}\text { Atividades de televisão, rádio, cinema, } \\
\text { gravação de som e imagem }\end{array}$ & 0,8182 \\
\hline Outros equipamentos de transporte & 31,3087 & Intermediação financeira e seguros & 0,77271 \\
\hline Demais transportes de carga & 25,5925 & $\begin{array}{l}\text { Serviços de arquitetura, engenharia, } \\
\text { testes e pesquisa e desenvolvimento }\end{array}$ & 0,77076 \\
\hline $\begin{array}{l}\text { Fabricação de químicos e resinas e } \\
\text { elastômeros }\end{array}$ & 13,8236 & $\begin{array}{l}\text { Atividades de vigilância, segurança e } \\
\text { investigação }\end{array}$ & 0,76634 \\
\hline Refino de petróleo e coque & 9,47674 & $\begin{array}{l}\text { Outras atividades profissionais, cientificas } \\
\text { e técnicas }\end{array}$ & 0,73797 \\
\hline Armazenagem e correio & 4,79528 & Telecomunicações & 0,72618 \\
\hline Transporte de carga hidroviário & 4,74863 & $\begin{array}{l}\text { Atividades jurídicas, contábeis e } \\
\text { consultoria e sedes }\end{array}$ & 0,68758 \\
\hline Agricultura, silvicultura & 3,06777 & $\begin{array}{l}\text { Defensivos agrícolas, tintas e químicos } \\
\text { diversos }\end{array}$ & 0,56977 \\
\hline
\end{tabular}


GONÇALVES, OLIVEIRA, JOHNSTON.

\begin{tabular}{|c|c|c|c|}
\hline Produtos de madeira - exclusive móveis & 2,63676 & $\begin{array}{l}\text { Desenvolvimento de sistema e outros } \\
\text { serviços de informação }\end{array}$ & 0,53952 \\
\hline $\begin{array}{l}\text { Alugueis não imobiliário e gestão de } \\
\text { propriedade não intelectual }\end{array}$ & 1,77521 & Serviços imobiliários e aluguel & 0,52843 \\
\hline $\begin{array}{l}\text { Manutenção, reparação e instalação de } \\
\text { máq. e equipamentos }\end{array}$ & 1,64551 & Edição, edição integrada e impressão & 0,49619 \\
\hline Outros serviços & 1,58412 & Serviços domésticos & 0,47547 \\
\hline Demais transporte de passageiros & 1,46607 & Perfumaria, higiene e limpeza & 0,25323 \\
\hline Educação mercantil & 1,28728 & $\begin{array}{l}\text { Produtos de metal - exclusive máquinas e } \\
\text { equipamentos }\end{array}$ & 0,22848 \\
\hline Água, esgoto e gestão de resíduos & 1,26218 & Outros produtos alimentares & 0,21406 \\
\hline Alojamento & 1,23405 & Transporte de carga ferroviário & 0,19204 \\
\hline Comércio & 1,09022 & Outras atividades administrativas & 0,17918 \\
\hline Saúde mercantil & 1,04788 & Impressão e reprodução de gravações & 0,16847 \\
\hline Alimentação & 1,02696 & Transporte rodoviário de passageiros & 0,16049 \\
\hline Pecuária inclusive apoio & 0,96747 & Artigos do vestuário e acessórios & 0,09995 \\
\hline Transporte hidroviário de passageiros & 0,96465 & Têxteis & 0,09236 \\
\hline Adm. Pública & 0,95665 & $\begin{array}{l}\text { Fabricação de produtos de minerais não- } \\
\text { metálicos }\end{array}$ & 0,08056 \\
\hline Transporte de carga rodoviário & 0,91923 & Abate e produtos & 0,07705 \\
\hline Construção & 0,90433 & $\begin{array}{l}\text { Peças e acessórios para veículos } \\
\text { automotores }\end{array}$ & 0,02506 \\
\hline $\begin{array}{l}\text { Energia elétrica, gás natural e outras } \\
\text { utilidades }\end{array}$ & 0,8763 & $\begin{array}{l}\text { Máquinas e equipamentos, exclusive } \\
\text { manutenção e reparos }\end{array}$ & 0,0189 \\
\hline
\end{tabular}

Fonte: Resultados da pesquisa. São os setores com maior representatividade na região em ordem decrescente.

Partindo do Quociente Locacional foi utilizado o mesmo método de Leivas e Feijó (2014) para a estimação do consumo intermediário e dos vetores de valor adicionado, valor bruto de produção e demanda final.

\section{Resultados e discussões}

Com o objetivo de observar a correlação entre os setores produtivos, foram calculados os índices de ligação para frente e para trás. Tais índices mostram quanto determinado setor é demandado pelos demais e o quanto cada setor demanda dos demais setores, respectivamente.

Considerando monetariamente, o índice de ligação para frente mostra o impacto de um aumento na demanda final de todos os setores sobre um determinado setor. Analisando a tabela 5 , um aumento de $R \$ 1,00$ na demanda final de todos os 
setores gera um impacto de $R \$ 3,68$ no valor da produção do setor do Comércio, pois é o setor que apresentou maior índice de ligação para frente.

Destacamos ainda que: agricultura e silvicultura; construção; transporte de carga rodoviário; demais transporte de passageiros; manutenção, reparação e instalação de máquinas e equipamentos, armazenagem e correio são os setores com maior índice de ligação para frente, ou seja, mais demandados por outros setores.

Já com relação ao índice de ligação para trás, o mesmo indica o impacto que um aumento na demanda final de determinado setor gera sobre a produção dos demais setores, isto é, um choque de $R \$ 1,00$ na demanda final do setor de Produtos de madeira - exclusive imóveis causa um impacto sobre a produção dos demais setores da ordem de $\mathrm{R} \$ 1,30$.

Cabe mencionar que os setores de outros equipamentos de transporte; atividades de televisão, rádio, cinema, gravação de som e imagem; produtos alimentares; defensivos agrícolas, tintas e químicos diversos; transporte hidroviário de passageiros; abate e produtos possuem junto com o setor de produtos de madeira os maiores índices de ligação para trás.

\begin{tabular}{|c|c|c|c|}
\hline SETORES & $\begin{array}{l}\text { Índice para } \\
\text { Frente }\end{array}$ & SETORES & $\begin{array}{c}\text { Índice } \\
\text { para Trás }\end{array}$ \\
\hline Comércio & 3,680075 & $\begin{array}{l}\text { Produtos de madeira - exclusive } \\
\text { móveis }\end{array}$ & 1,301138 \\
\hline Agricultura, silvicultura & 2,090295 & Outros equipamentos de transporte & 1,277368 \\
\hline Construção & 1,818456 & $\begin{array}{l}\text { Atividades de televisão, rádio, } \\
\text { cinema, gravação de som e imagem }\end{array}$ & 1,218609 \\
\hline Transporte de carga rodoviário & 1,772845 & Outros produtos alimentares & 1,164402 \\
\hline SETORES & $\begin{array}{l}\text { İndice para } \\
\text { Frente }\end{array}$ & SETORES & $\begin{array}{c}\text { Índice } \\
\text { para Trás }\end{array}$ \\
\hline Demais transporte de passageiros & 1,687791 & $\begin{array}{l}\text { Defensivos agrícolas, tintas e } \\
\text { químicos diversos }\end{array}$ & 1,161163 \\
\hline $\begin{array}{l}\text { Manutenção, reparação e instalação } \\
\text { de máq. e equipamentos. }\end{array}$ & 1,623724 & Transporte hidroviário de passageiros & 1,150702 \\
\hline Armazenagem e correio & 1,501269 & Abate e produtos & 1,134584 \\
\hline Outros serviços & 1,424237 & Transporte de carga hidroviário & 1,120807 \\
\hline $\begin{array}{l}\text { Produtos de madeira - exclusive } \\
\text { móveis }\end{array}$ & 1,420869 & $\begin{array}{l}\text { Fabricação de químicos e resinas e } \\
\text { elastômeros }\end{array}$ & 1,114631 \\
\hline Intermediação financeira e seguros & 1,343452 & Outros serviços & 1,085448 \\
\hline Água, esgoto e gestão de resíduos & 1,26183 & $\begin{array}{l}\text { Fabricação de celulose e produtos } \\
\text { de papel }\end{array}$ & 1,083726 \\
\hline
\end{tabular}


GONÇALVES, OLIVEIRA, JOHNSTON.

\begin{tabular}{l|c|l|c}
\hline Alimentação & 1,204514 & Têxteis & 1,067539 \\
\hline Produção florestal, pesca e aquicultura & 1,176562 & Telecomunicações & 1,062628 \\
\hline $\begin{array}{l}\text { Energia elétrica, gás natural e outras } \\
\text { utilidades }\end{array}$ & 1,15653 & Construção & 1,047826 \\
\hline $\begin{array}{l}\text { Fabricação de químicos e resinas e } \\
\text { elastômeros }\end{array}$ & 1,108227 & Transporte rodoviário de passageiros & 1,047658 \\
\hline Outros equipamentos de transporte & 1,107056 & Demais transportes de carga & 1,033909 \\
\hline Educação mercantil & 1,096397 & Água, esgoto e gestão de resíduos & 1,021324 \\
\hline $\begin{array}{l}\text { Produtos de metal - exclusive } \\
\text { máquinas e equipamentos }\end{array}$ & 1,068244 & Saúde mercantil & 1,017567 \\
$\begin{array}{l}\text { Outras atividades profissionais, } \\
\text { científicas e técnicas }\end{array}$ & 1,062468 & & \\
\hline Fonte: Elaboração dos autores com & \multicolumn{2}{|l}{}
\end{tabular}

Fonte: Elaboração dos autores como base nos resultados da pesquisa.

Na tabela 6, é possível identificar os setores-chave da economia. Segundo o critério usado em Najberg e Vieira (1996), setores-chave são aqueles que apresentam índice de interligação para trás e para frente maior que um (1) simultaneamente. Com isso, é possível identificar seis setores-chave da região da Costa Sul: construção; outros serviços; produtos de madeira - exclusive móveis; água, esgoto e gestão de resíduos; fabricação de químicos e resinas e elastômeros e outros equipamentos de transporte são os setores de destaque na região.

Logo, os resultados indicam que a Costa Sul é extremamente dependente de atividades ligadas a produção de florestas (produtos de madeira e fabricação de químicos e resinas) e atividades relacionadas a indústria naval (outros equipamentos de transporte).

\section{Tabela 6: Setores chaves da Costa Sul}

\begin{tabular}{l|c|c}
\hline SETORES & \multicolumn{2}{|c}{ Índice } \\
\hline Construção & Frente & Trás \\
\hline Outros serviços & 1,8185 & 1,0478 \\
\hline Produtos de madeira - exclusive móveis & 1,4242 & 1,0854 \\
\hline Água, esgoto e gestão de resíduos & 1,4209 & 1,3011 \\
\hline Fabricação de químicos e resinas e elastômeros & 1,2618 & 1,0213 \\
\hline Outros equipamentos de transporte & 1,1082 & 1,1146 \\
\hline
\end{tabular}

Fonte: Elaboração dos autores como base nos resultados da pesquisa.

Como complemento à análise, os multiplicadores de impacto da Costa Sul encontrados possibilitaram analisar os impactos diretos e indiretos ocasionados por 
mudanças na demanda final, ou seja, como um choque na demanda final de determinado setor desencadeia uma série de estímulos intersetoriais, afetando quase todos setores da economia. Porsse (2003) cita que o modelo é uma ferramenta bastante importante para o planejamento econômico, pois podem auxiliar no processo de tomada de decisão de políticas públicas auxiliando o desenvolvimento regional, já que mostra quais setores têm maior impacto sobre a produção, o emprego e o valor adicionado.

Portanto, analisando separadamente, o multiplicador de produção mostra quais setores são relevantes para nível de produção da região, ou seja, o setor que tem maior relação com outros setores na economia da região. Isso quer dizer que, se a demanda final desses setores aumentar em $R \$ 1,00$, qual será o incremento na produção, por exemplo, no caso de produtos de madeira um incremento de $R \$ 1,7481$ no setor.

Com isso, a partir da tabela 7 percebemos que os setores da região que apresentam maiores multiplicadores de produção são respectivamente: produtos de madeira - exclusive móveis; outros equipamentos de transporte; atividades de televisão, rádio, cinema, gravação de som e imagem; outros produtos alimentares; defensivos agrícolas, tintas e químicos diversos; transporte hidroviário de passageiros; abate e produtos; transporte de carga hidroviário; fabricação de químicos e resinas e elastômeros.

Outro multiplicador de suma importância é do valor adicionado, que considera os setores que possuem maior efeito multiplicador na geração de valor. Portanto, como demonstra a tabela 7, os setores da Costa Sul são, respectivamente: comércio; serviços imobiliários e aluguel; educação mercantil; demais transporte de passageiros; produção florestal, pesca e aquicultura; agricultura, silvicultura; transporte de carga rodoviário. No sentido oposto, os setores de outros produtos alimentares e abate e produtos possuem pouca contribuição para a geração de valor adicionado. 


\begin{tabular}{|c|c|c|c|}
\hline SETORES & M. PROD. & SETORES & M. VAB \\
\hline Produtos de madeira - exclusive móveis & 1,7481 & Comércio & 1,4723 \\
\hline Outros equipamentos de transporte & 1,7162 & Serviços domésticos & 1,0000 \\
\hline $\begin{array}{l}\text { Atividades de televisão, rádio, cinema, gravação } \\
\text { de som e imagem }\end{array}$ & 1,6372 & Serviços imobiliários e aluguel & 0,9725 \\
\hline Outros produtos alimentares & 1,5644 & Educação mercantil & 0,9631 \\
\hline Defensivos agrícolas, tintas e químicos diversos & 1,5601 & $\begin{array}{l}\text { Demais transporte de } \\
\text { passageiros }\end{array}$ & 0,8586 \\
\hline Transporte hidroviário de passageiros & 1,5460 & Armazenagem e correio & 0,7922 \\
\hline Abate e produtos & 1,5243 & $\begin{array}{l}\text { Intermediação financeira e } \\
\text { seguros }\end{array}$ & 0,7858 \\
\hline Transporte de carga hidroviário & 1,5058 & $\begin{array}{l}\text { Produção florestal, pesca e } \\
\text { aquicultura }\end{array}$ & 0,7704 \\
\hline Fabricação de químicos e resinas e elastômeros & 1,4975 & Agricultura, silvicultura & 0,7376 \\
\hline Outros serviços & 1,4583 & Transporte de carga rodoviário & 0,7006 \\
\hline Fabricação de celulose e produtos de papel & 1,4560 & $\begin{array}{l}\text { Atividades de vigilância, } \\
\text { segurança e investigação }\end{array}$ & 0,6619 \\
\hline Transporte de carga ferroviário & 1,4410 & $\begin{array}{l}\text { Desenvolvimento de sistema e } \\
\text { outros serviços de informação }\end{array}$ & 0,6366 \\
\hline Têxteis & 1,4343 & $\begin{array}{l}\text { Energia elétrica, gás natural e } \\
\text { outras utilidades }\end{array}$ & 0,6084 \\
\hline Telecomunicações & 1,4277 & $\begin{array}{l}\text { Atividades jurídicas, contábeis e } \\
\text { consultoria e sedes }\end{array}$ & 0,5896 \\
\hline Construção & 1,4078 & $\begin{array}{l}\text { Água, esgoto e gestão de } \\
\text { resíduos }\end{array}$ & 0,5202 \\
\hline Educação mercantil & 1,0979 & Perfumaria, higiene e limpeza & 0,1199 \\
\hline Peças e acessórios para veículos automotores & 1,0968 & $\begin{array}{l}\text { Outros equipamentos de } \\
\text { transporte }\end{array}$ & 0,1001 \\
\hline $\begin{array}{l}\text { Manutenção, reparação e instalação de máq. E } \\
\text { equipamentos }\end{array}$ & 1,0826 & $\begin{array}{l}\text { Máquinas e equipamentos, } \\
\text { inclusive manutenção e reparos }\end{array}$ & 0,0978 \\
\hline $\begin{array}{l}\text { Atividades de vigilância, segurança e } \\
\text { investigação }\end{array}$ & 1,0788 & Outros produtos alimentares & 0,0833 \\
\hline Serviços imobiliários e aluguel & 1,0423 & Abate e produtos & 0,0423 \\
\hline
\end{tabular}

Fonte: Elaboração dos autores como base nos resultados da pesquisa.

Por fim, tem-se o multiplicador de emprego que, indica quantos empregos seriam gerados dado a alteração nos setores, ou seja, para cada um milhão de reais são gerados um valor $X$ de empregos diretos e indiretos. Analisando a tabela 8 , destacamos os melhores e piores setores na geração de empregos. A cada um milhão de reais, são gerados em torno de 69 empregos do setor de atividades de vigilância, segurança e investigação. Outro setor de destaque é o comércio que originaria 25 empregos. Além disso, são relevantes na geração de empregos da região os setores de demais transporte de passageiros; desenvolvimento de sistemas, e outros serviços de informação; educação mercantil; têxteis; armazenagem e correio; alojamento e produtos de madeira - exclusive móveis. 
Tabela 8: Multiplicador de emprego da Costa Sul: Setores selecionados

\begin{tabular}{|c|c|c|}
\hline SETORES & M. EMP & Ranking \\
\hline Atividades de vigilância, segurança e investigação & 69,7740 & $1^{0} \underline{0}$ \\
\hline Comércio & 25,3871 & $2^{0}$ \\
\hline Demais transporte de passageiros & 18,8807 & $3^{\circ}$ \\
\hline Transporte de carga rodoviário & 18,7440 & $4^{\circ}$ \\
\hline Desenvolvimento de sistema e outros serviços de informação & 17,6979 & $5^{0}$ \\
\hline Educação mercantil & 16,6804 & $6^{0}$ \\
\hline Têxteis & 15,7183 & $7^{0}$ \\
\hline Armazenagem e correio & 15,5051 & $8^{0}$ \\
\hline Alojamento & 14,1300 & 90 \\
\hline Produtos de madeira - exclusive móveis & 12,7008 & $10^{\circ}$ \\
\hline Alimentação & 11,7998 & $11^{\circ}$ \\
\hline Outros serviços & 10,8523 & $12^{0}$ \\
\hline Agricultura, silvicultura & 10,0178 & $13^{\circ}$ \\
\hline Saúde mercantil & 9,9133 & $14^{\circ}$ \\
\hline Construção & 9,8594 & $15^{\circ}$ \\
\hline Abate e produtos & 0,8286 & $47^{\circ}$ \\
\hline Refino de petróleo e coque & 0,2647 & $48^{\circ}$ \\
\hline Demais transportes de carga & 0,2016 & $49^{\circ}$ \\
\hline Transporte hidroviário de passageiros & 0,1569 & $50^{\circ}$ \\
\hline Transporte de carga ferroviário & 0,1157 & $51^{\circ} \stackrel{0}{2}$ \\
\hline
\end{tabular}

Fonte: Elaboração dos autores como base nos resultados da pesquisa.

Destarte, avaliando os resultados, é importante observar que estes multiplicadores devem ser analisados com cautela, visto que o setor do comércio apresentou um elevado multiplicador na produção e no emprego, porém não é um setor-chave. Diante dos resultados, podemos observar que não temos apenas um setor-chave e que a região da Costa Sul é bem diversificada na sua estrutura produtiva. Deste modo, as políticas públicas voltadas a elevar o crescimento podem ser direcionadas para os diferentes setores-chaves, de acordo com o propósito e objetivo a serem alcançados.

\section{Considerações Finais}

O objetivo deste artigo foi estimar uma Matriz Insumo Produto da Costa Sul do Rio Grande do Sul, buscando conhecer o perfil econômico a partir dos indicadores de análise. A matriz foi regionalizada utilizando o método do Quociente Locacional 
partindo de uma matriz calculada para o Rio Grande do Sul em 2011, baseada na estrutura setorial na matriz 2010 nacional. Foram utilizados dados do IBGE 2011, da Relação Anual de Informações Sociais (RAIS).

Os resultados dos multiplicadores de renda e emprego indicaram que os setores de maior impacto foram: produção florestal, pesca e aquicultura; armazenagem e correio; construção; comércio; agricultura e silvicultura e transporte de carga rodoviário. Com relação ao multiplicador da produção os setores com maior representatividade foram: produtos de madeira; outros equipamentos para transporte; outros produtos alimentares; defensivos agrícolas; abate e produtos e fabricação de químicos, resinas e elastômeros.

Além disso, foram considerados setores chaves da região com base nos índices de ligação para frente e para trás: construção; outros serviços; produtos de madeira - exclusive móveis; água, esgoto e gestão de resíduos; fabricação de químicos e resinas e elastômeros e outros equipamentos de transporte.

A região possui um riquíssimo ecossistema litorâneo que compreende a laguna dos Patos e o seu estuário no município do Rio Grande, onde se localiza um dos maiores portos do Brasil, a binacional lagoa Mirim a lagoa do peixe entre Tavares e Mostardas, a lagoa Mangueira em Santa Vitória do Palmar, a estação ecológica do Taim além de centenas de quilômetros de praias desertas. Em linhas gerais, tem grande representatividade as atividades relacionadas à produção florestal, atividade portuária e agronegócio.

Cabe salientar que estas atividades causam impactos sobre os ecossistemas locais e sobre os serviços prestados pela natureza. Os recursos pesqueiros apresentam uma forte tendência de queda provocada possivelmente pela intensa atividade a partir da década de 1970, grande parte das atividades florestais ocorre nas zonas costeiras, que são ambientes sensíveis às atividades humanas e a agricultura é responsável por grande parte da poluição química das lagoas locais.

O presente trabalho pode ser considerado como pioneiro por avaliar o contexto econômico de uma região com grande potencial, por isso, pesquisas futuras devem incluir a desagregação das atividades principais com a incorporação de um módulo satélite que avalie os impactos ambientais sobre os principais setores da região. 


\section{REFERÊNCIAS.}

BRENE, P. R. A; SESSO FILHO, U. A; COSTA, A. J. D; RANGEL, R. R. Estimativa da matriz de insumo-produto do município de São Bento do Sul no Estado de Santa Catarina. Revista Brasileira de Gestão e Desenvolvimento Regional. v.7, n.3, p. 250-269, set./dez., 2011.

FUNDAÇÃO DE ECONOMIA E ESTATÍSTICA DO RS (FEE). Dados sobre o Rio Grande do Sul por mesorregião. Disponível em: http://feedados.fee.tche.br/feedados/ Acesso em: 25/08/2017.

FIGUEIREDO, M. G. F; BARROS, A. L. M; GUILHOTO, J. J. M. Relação econômica dos setores agrícolas do Estado do Mato Grosso com os demais setores pertencentes tanto ao Estado quanto ao restante do Brasil. Revista de Economia e Sociologia Rural. Rio de Janeiro, v.43, n.03, p. 557-575, 2005.

GONÇALVES, R. R. Avaliação de impactos econômicos de melhorias em transporte no rio grande do sul: uma abordagem com equilíbrio geral dinâmico. Tese (Doutorado em Economia) - Pontifícia Universidade Católica do Rio Grande do Sul, Porto Alegre, 2018.

GUILHOTO, J. J. M. Input-Output Analysis: Theory an Foundations. Departamento de Economia. FEA-USP. Versão Revisada. 2011.

HIRSCHMAN, A. O. The strategy of economic development. New Haven: Yale University Press, 1958.

ISARD, W. Interregional and regional input-output analysis: a model of a spaceeconomy. Review of Economics and Statistics, Cambridge-Mass.: Elsevier, v.33, n.4, p. 319-328, 1951.

ISARD, W.; KUENNE, R. The impact of steel upon the greater New York-Philadelphia industrial region. Review of economics and statistics, v.35, n.4, p. 289-301, 1951.

LEIVAS, P. H; FEIJÓ, F. T. Estrutura produtiva e multiplicadores de impacto inter setorial do Conselho Regional de Desenvolvimento da Região Sul (Corede Sul) do Rio Grande do Sul: uma análise de insumo-produto. Porto Alegre: Ensaios FEE, v.35, n.2, p. 521-554, dez. 2014.

LEONTIEF, W. Quantitative Input-Output Relations in the Economic Systems of the United States. Review of Economics and Statistics, v.18, n.3, p. 105-25, 1936.

MILLER, R. E.; BLAIR, P. D. Input-output analysis: foundations and extensions. Cambridge: Cambridge University Press, 2009.

NAJBERG, S.; VIEIRA, S. P. Modelos de geração de emprego aplicados à economia brasileira: 1985/95, Revista do BNDES, v.3. n.5, p. 63-86. Rio de Janeiro, 1996. 
NUNES, P. A.; MELO, C. O. Estrutura Produtiva da Mesorregião Sudeste Paranaense com Abordagem Insumo-Produto. Revista Paranaense de Desenvolvimento. n.123, p. 179-212, jul./dez. 2012.

PARRÉ, J. L. O agronegócio nas macrorregiões brasileiras. 191 f. Tese (Doutorado em Economia Aplicada) - Escola Superior de Agricultura "Luiz de Queiroz", Universidade de São Paulo, Piracicaba, 2000.

PEROBELLI, F. S; MATTOS, R. S; FARIA. W. R. Interações energéticas entre o Estado de Minas Gerais e o restante do Brasil: uma análise inter-regional de insumo-produto. Revista Economia Aplicada, v.11, n.1, p. 113-130, 2007.

PORSSE, A. A.; HADDAD, E. A.; RIBEIRO, E. P. Estimando uma matriz de insumoproduto inter-regional Rio Grande do Sul: restante do Brasil. São Paulo: Núcleo de Economia Regional e Urbana da USP: NEREUS2003, 2003.

PORSSE, A. A.; PEIXOTO, F. C.; PALERMO, P. U. Matriz de Insumo-Produto interregional Rio Grande do Sul-restante do Brasil 2003: metodologia e resultados. Porto Alegre: FEE, (Textos Para Discussão FEE, n. 38), 2008.

PORSSE, A. A.; HADDAD, E. A.; RIBEIRO, E. P. Estimando uma matriz de insumo produto interregional Rio Grande do Sul-Restante do Brasil. In: ENCONTRO BRASILEIRO DE ESTUDOS REGIONAIS, Belo Horizonte. Anais... Belo Horizonte: Editor institucional, 2003.

RASMUSSEN, P. N. Studies in intersectoral relations. North Holland, Amsterdam, 1956.

RELAÇÃO ANUAL DE INFORMAÇÕES SOCIAIS (RAIS): Disponível em:

http://www.rais.gov.br/sitio/index.jsf Acesso em: 20/04/2017.

RIBEIRO, L. C. S; MONTENEGRO, R. L. G; PEREIRA, R. M. Estrutura econômica e encadeamentos setoriais de minas gerais: uma Sergipe, 2006: Uma contribuição através da matriz de insumo-produto. Revista Econômica do Nordeste. v.43, n.4, p. 96$118,2013$.

RIBEIRO, L. C. S; MONTENEGRO, R. L. G; PEREIRA, R. M. Estrutura econômica e encadeamentos setoriais de minas gerais: Uma contribuição para as políticas de planejamento. Revista Planejamento e Políticas Públicas, n. 41. jul./dez, p. 261-290,. 2013.

TALAMINI, E.; PEDROZO, E. Á. Matriz do tipo insumo-produto (MIP) e alguns indicadores para gestão e planejamento de propriedades rurais: uma aplicação prática. Revista Teoria e Evidencia Econômica, Passo Fundo: UPF, v.12, n.23, p.25-43, 2004.

WIEBUSCH, F. C. Estrutura produtiva e multiplicadores de insumo produto do COREDE Vale do Taquari. Dissertação (Mestrado em Economia) - Pontifícia Universidade Católica do Rio Grande do Sul, Porto Alegre, 2007. 


\section{NOTAS DE AUTOR}

\section{CONTRIBUIÇÃO DE AUTORIA}

Rodrigo da Rocha Gonçalves - Concepção, Coleta de dados, manipulação dos dados, estimação da Matriz Insumo Produto, Elaboração do manuscrito, Análise dos resultados, revisão e aprovação da versão final do trabalho.

Cassius Rocha de Oliveira - Concepção, Coleta de dados, Contextualização da região, Elaboração do manuscrito, Análise dos resultados, revisão e aprovação da versão final do trabalho.

Fernanda Lopes Johnston - Concepção, Coleta de dados, Elaboração do manuscrito, Análise dos resultados, revisão e aprovação da versão final do trabalho.

\section{FINANCIAMENTO}

Não se aplica.

\section{CONSENTIMENTO DE USO DE IMAGEM}

Não se aplica.

\section{APROVAÇÃO DE COMITÊ DE ÉTICA EM PESQUISA}

Não se aplica.

\section{CONFLITO DE INTERESSES}

Não se aplica.

LICENÇA DE USO - uso exclusivo da revista

Este artigo está licenciado sob a Licença Creative Commons CC-BY. Com essa licença você pode compartilhar, adaptar, criar para qualquer fim, desde que atribua a autoria da obra.

HISTÓRICO - uso exclusivo da revista

Recebido em: 28-05-2018

Aprovado em: 18-09-2018 